\title{
Thermo-Chemical Decomposition Study of Polyurethane Elastomer Through Glycerolysis Route with Using Crude and Refined Glycerine as a Transesterification Agent
}

\author{
Janusz Datta $^{1} \cdot$ Patrycja Kopczyńska $^{1} \cdot$ Diego Simón $^{2} \cdot$ Juan F. Rodríguez $^{2}$
}

Published online: 12 January 2017

(C) The Author(s) 2017. This article is published with open access at Springerlink.com

\begin{abstract}
Due to the increasing amount of polyurethane waste, chemical recycling of these materials is a topic of growing interest for many researchers. The primary purpose of polyurethane feedstock recycling is to recover the starting polyol. In this study glycerolysis using glycerine from two sources and two purity grades is proposed as a method of chemical recycling. The main effort of this paper focuses on the employment of commercial glycerine of analytical grade and waste glycerine without purification derived from the biodiesel production, as a decomposing agent for polyurethane recycling. In this study, the influence of polyurethane to glycerine mass ratio (PU/GL) and the type of decomposing agent on the chemical structure by FTIR, ${ }^{1} \mathrm{H}$ NMR and GPC was examined. FTIR analysis of the glycerolysates showed absorption peaks similar to the virgin polyol. Those results are in compliance with GPC chromatograms, which showed for all samples, welldefined peak at ca. 13 min of retention time. The molecular weight of glycerolysates was ranging from 800 to $1300 \mathrm{~g} \mathrm{~mol}^{-1}$ depending on PU/GL mass ratio. The novel decomposition agent, namely waste glycerine derived from biodiesel production was successfully used in glycerolysis process.
\end{abstract}

Janusz Datta

jandatta@pg.gda.pl

1 Chemical Faculty, Department of Polymer Technology, Gdansk University of Technology, G. Narutowicza Street 11/12 80-233 Gdansk, Poland

2 Department of Chemical Engineering, Institute for Chemical and Environmental Technology (ITQUIMA), University of Castilla-La Mancha, Avda. Camilo José Cela 1213071 Ciudad Real, Spain
Keywords Recycling - Polyurethane waste - Elastomers · Glycerolysis · Glycerine

\section{Introduction}

Global polyurethanes (PUs) production is currently more than 15 million tons and is expected to reach over 22 million tons by 2020 [1]. The growing trend of polyurethane industrial consumption is caused due to industrial applications and technological developments. As greater the consume, the amount of produced waste is growing. In Europe, polyurethane foam waste amount generated during production process was estimated to be 10,000 tons a year in 2003. The total polyurethane waste produced by the customer is ranging from approx. 2.1 Mt a year to $3.6 \mathrm{Mt}$ a year in Europe. About Europe figures, the waste management for polyurethane foams, as for plastics in general, is divided into three traditional processes:

- accumulation in landfills (0.9 Mt a year)

- incineration (0.7 Mt a year)

- recycling (0.5 Mt a year).

Only $58 \%$ of polyurethanes are valorised in some way. Figure 1 presents the percentage participation of polyurethane waste management methods. The low density and the extensive use of landfills as a final destiny of PU waste are generating a new problem in relation with the space that this kind of waste occupies in the municipal landfills. To reduce the environmental impact of polyurethane waste, creative and profitable recycling methods are being proposed [2, 3].

In the recent years, many researchers have focused their efforts on finding solutions and new approaches for 


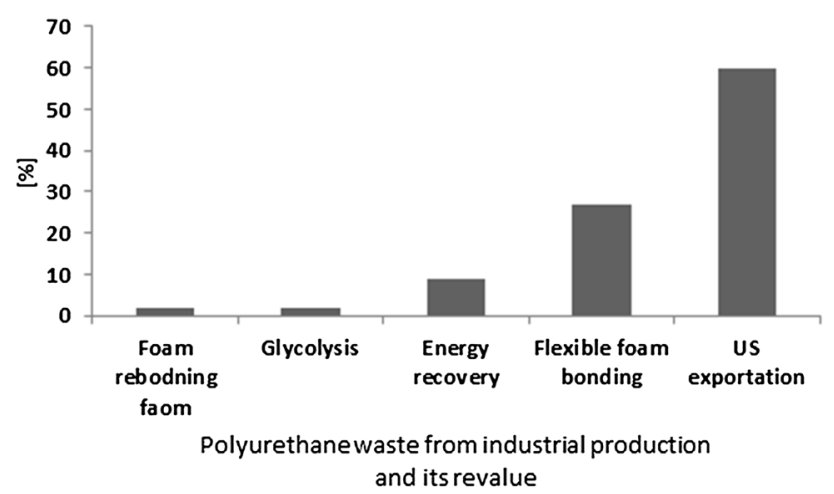

Fig. 1 Handling methods of polyurethane waste [3]

polyurethane waste treatment $[4,5]$. Mechanical recycling can be done i.e., by regrinding polyurethane foams into powders, which could be used in the production of new foam as filler. Chemical recycling of polyurethane waste is used due to the reversibility of polymerisation. Feedstock recycling can lead to polyol recovery by various methods such as hydrolysis, aminolysis, glycolysis, hydroglycolysis. Energy recovery is suitable only for materials which are difficult to recycle such as PU laminates to wood, leather or fabrics [6-9].

Glycolysis is the most widely used chemical recycling method for PU. In this reaction polyurethane scraps react with diols at temperatures around $200{ }^{\circ} \mathrm{C}$. The polyurethane structure is degraded by transesterification reactions of urethane bond with glycols [10]. Many researchers have been investigating glycolysis process. They performed studies along with the influence of glycol, catalyst, time and temperature used during the glycolysis reaction [11-16]. Datta [17] examined the influence of glycols on the chemical structure of obtained products. He In that work, glycols ranging from ethylene glycol to hexane-1,6-diol were used. It was established that the glycol has no significant influence on the chemical composition of glycolysates. Molero et al. [18] carried out polyurethane glycolysis with DEG (diethylene glycol) and stannous octoate as a glycolysis agent and catalyst, respectively. The work indicated that the employment of active catalyst allows obtaining high decomposition rates and high purity of recovered polyol. Glycerine has also been proposed as a decomposing agent with promising results [19]. Nikje and Mohammadi used sorbitol/ glycerine/water mixture as glycolysis agent in flexible polyurethane recycling [20]. The glycolysis can proceed by two ways in one phase or split-phase. In this last case, the reaction mixture after the reaction is splitted into two phases. The upper phase is mainly constituted by the polyols employed in the formation of PUs with a high purity grade, regardless the kind of flexible PU foam treated

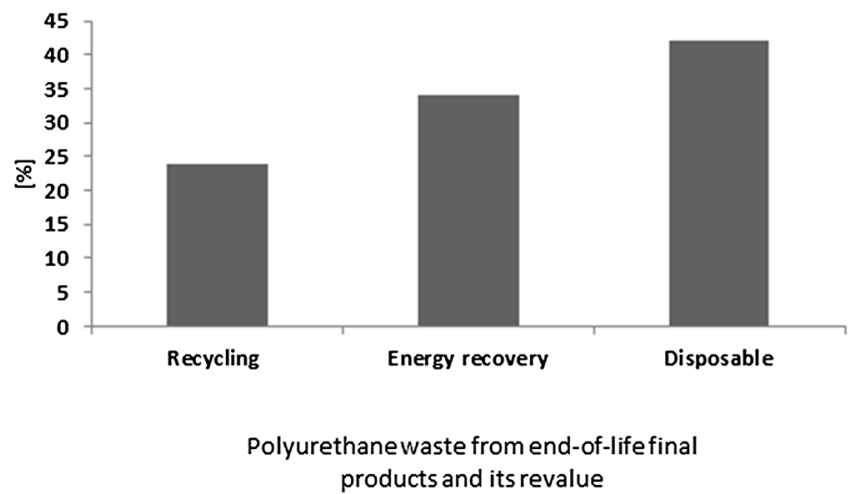

[21-23] and the bottom phase containing the excess of the solvolytic agent and different amino compounds from the isocyanate part of the PU, generally aromatic amines similar to toluendiamine $[5,24,25]$. Lately, the utilisation of crude glycerol and glycerine was reported in the literature [26, 27]. The application of crude (or waste) glycerine from biodiesel production as a decomposition agent allows obtaining recovered polyol in a similar manner as in glycolysis reaction.

Due to pro-ecological attitude, oil industry invests a great quantity of money in renewable resources and try to replace crude oil using i.e., biodiesel. Biodiesel is produced by reacting a vegetable oil or animal fat with alcohol (e.g., methanol) in the presence of a catalyst, known as transesterification (Fig. 2). The main products are methyl esters, and they are called biodiesel. Crude glycerine is obtained as a by-product from biodiesel production. It is estimated that approx. one kilogram of glycerine phase is produced during the production of $10 \mathrm{~kg}$ biodiesel. After the transesterification, a settling is carried out to separate product on two phase: ester and glycerine phase. For ordinary purposes, such a waste glycerine can be further purified and refined (from 50 to even $99.5 \%$ after refining). The refined glycerine can be used in pharmaceutical, chemical industry and also in alkyd resins, cellulose coatings, but the cost of purification and refining are high [28, 29].

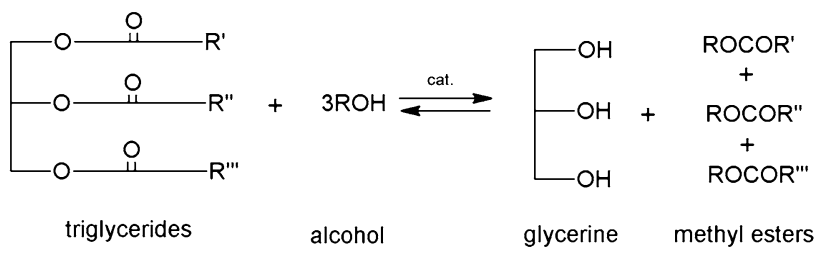

Fig. 2 A schematic representation of the transesterification of triglycerides (vegetable oil or animal fat) with alcohol to produce fatty acid methyl esters (biodiesel). $\mathrm{R}^{\prime}, \mathrm{R}^{\prime \prime}$ and $\mathrm{R}^{\prime \prime \prime}$ are long hydrocarbon chains, sometimes called fatty acid chains 
In this current work of research in polyurethane recycling, we decided to study the glycerolysis of elastomeric polyurethane waste using two types of glycerine (waste/ non-refined and distilled glycerine) as a decomposing agent at atmospheric pressure. The glycerolysis reaction was performed in various polyurethane/glycerine ratios to determinate the influence of polyurethane waste excess on glycerolysis products. The obtained semi-products were characterised using Fourier transform infrared and ${ }^{1} \mathrm{HNMR}$ spectroscopies, gel permeation chromatography (GPC) and physical and chemical properties.

\section{Experimental}

\section{Glycerolysis}

Polyurethane elastomer waste based on polyester polyol $\left(\mathrm{M}_{\mathrm{n}}=2000 \mathrm{~g} \mathrm{~mol}^{-1}\right.$ [information provided by manufacturer] $\mathrm{M}_{\mathrm{n}}=1240 \mathrm{~g} \mathrm{~mol}^{-1}$ [information taken from GPC analysis], $\mathrm{OH} 54-58 \mathrm{mg} \mathrm{KOH} \mathrm{g}^{-1}$, acidity $0.05 \mathrm{mg} \mathrm{KOH}$ $\mathrm{g}^{-1}$ ) and 4,4'-methyldiphenyl diisocyanate (MDI, Borsodchem, Hungary) was reacted in various mass ratios with two types of glycerine. Waste glycerine with purity $80 \%$ (Rafinferia Trzebinia S.A., Poland) and distilled glycerine with purity 99.5\% (STANLAB Sp.J., Poland) were used as a decomposing agent and potassium acetate of $0.5 \mathrm{wt} . \%$ on polyurethane amount (POCH, Poland) as a catalyst in order to accelerate the reaction. Glycerolysis reaction was carried out at following PU/glycerine mass ratios: $2: 1$; $4: 1$; $6: 1 ; 8: 1$ and $10: 1$. The reaction was carried out in a $2 \mathrm{~L}$ steel reactor with a mechanical stirrer and reflux condenser in the temperature $225-230^{\circ} \mathrm{C}$. The reaction time ranged from 95 to 145 min depending on the PU/GL mass ratio [30] (Table 1). Glycerine was not separated from the product after the process of glycerolysis. Table 1 presents codes of prepared samples.

Table 1 Codes of glycerolysis products

\begin{tabular}{llll}
\hline Code of material & $\begin{array}{l}\text { PU/GL } \\
\text { mass ratio }\end{array}$ & Type of glycerine & Time (min) \\
\hline WGL 2 & $2 / 1$ & Waste glycerine & 95 \\
WGL 4 & $4 / 1$ & Waste glycerine & 100 \\
WGL 6 & $6 / 1$ & Waste glycerine & 105 \\
WGL 8 & $8 / 1$ & Waste glycerine & 120 \\
DGL 6 & $6 / 1$ & Distilled glycerine & 105 \\
DGL 10 & $10 / 1$ & Distilled glycerine & 145 \\
\hline
\end{tabular}

\section{Product Characterisation}

To investigate the chemical structure of obtained semiproducts, the FTIR analysis was executed. Spectroscopic analysis of glycerolysates was carried out using a FTIR Nicolet 8700 spectrophotometer (Thermo Electron Corporation) and ATR technique. The Specac Heated Golden Gate single reflection diamond ATR accessory was used, and it operated up to $200^{\circ} \mathrm{C}$. Spectra were registered at room temperature for wavenumbers ranging from 500 to $4500 \mathrm{~cm}^{-1}$ at $4 \mathrm{~cm}^{-1}$ nominal resolution with 64 scans.

${ }^{1} \mathrm{H}$ NMR spectra of glycerolysates and polyol were recorded with a Bruker AV $400 \mathrm{MHz}$ spectrometer in a $\mathrm{CDCl}_{3}$ solvent at ambient temperature. The simulation and iteration of spectra were carried out using Bruker software.

Gel permeation chromatography (GPC) was used to determine the molecular weight distribution (MWD) as well as the concentration of polyol in the products of the polymers. Measurements were performed with a Viscotek GPCmax VE- 2001 TDA 302 Detectors, equipped with two columns (Waters Styragel HR2 and Styragel HR0.5) using THF as eluent at $40^{\circ} \mathrm{C}$ (flow: $1 \mathrm{~mL} \mathrm{~min}^{-1}$ ) and a refractive index detector. Poly(ethylene glycol) standards (from Waters, USA) were used for MWD calibration and mixtures of the industrial starting polyether polyol, and DEG were used as concentration standards. The measurement was performed in the Department of Chemical Engineering of the University of Castilla-La Mancha.

Hydroxyl number of the recovered polyols was determined by a standard titration method (ASTM D 427488). Each experimental analysis was repeated at least twice, and the average value has been given. All chemicals used in this analyse were of the quality required in the standards.

Based on hydroxyl value, functionality was calculated from Eq. 1:

$f=\frac{M_{n} O H_{\text {number }}}{56100}$

where $M_{n}$ is the number average molecular weight and 56100 is the molecular weight of $\mathrm{KOH}$ in $\mathrm{mg} \cdot \mathrm{mol}^{-1}$.

Viscosity analyses were performed by using rotary rheometer R/S-CPS+ (Brookfield, USA). Measurements were conducted with controlled shear rate (CSR). The following program was applied: the constant shear rate of $300 \mathrm{~s}^{-1}$ for $180 \mathrm{~s}$, temperature $70^{\circ} \mathrm{C}$.

Density was determined using pycnometer by a standard method (PN-EN ISO 1675).

\section{Results and Discussion}

The structures of obtained glycerolysates were confirmed by FTIR spectroscopy (Fig. 5a-c). In Fig. 5a the 
comparison of WGL 6 and DGL 6 samples is presented. The spectra are very similar to the absorption bands and peaks appear at the same wave number with the same intensity. Therefore, it can be concluded that the type of used glycerine does not influence much on the glycerolysate structure. Characteristic stretching vibrations of $-\mathrm{NH}$ bond occur at $3363 \mathrm{~cm}^{-1}$ coming from urethane bond and band in the range $3600-3200 \mathrm{~cm}^{-1}$ coming from the $\mathrm{OH}$ groups of glycerine can be observed. Intensive absorption bands at wavenumber $2950-2870 \mathrm{~cm}^{-1}$ correspond to symmetric bending oscillation of $-\mathrm{CH}_{2}$ and $-\mathrm{CH}_{3}$ groups. The presence of ester bonds in the structure is confirmed by the strong absorption band at $1728 \mathrm{~cm}^{-1}$ of carbonyl group $-\mathrm{C}=\mathrm{O}$. The absorption band at $1612 \mathrm{~cm}^{-1}$ corresponds to bending vibrations of $-\mathrm{NH}$ and indicates that glycerolysates contain carbamates. The schematic process of forming carbamates during glycerolysis is shown in Figs. 3 and 4. Urea bonds are absent in the media (no bands in the region of $1640 \mathrm{~cm}^{-1}$ ) since they can be broken by the glycerine as well. The region ca. $1516 \mathrm{~cm}^{-1}$ corresponds to the stretching vibrations of $-\mathrm{NH}$ in primary amines. Therefore absorption bands at 1612 and $1516 \mathrm{~cm}^{-1}$ are related to the bending vibrations of amine groups derived from 4,4'- methylenediphenyl diisocyanate which has been dissolved within the products [31, 32].

Bands visible at region $1540-1350 \mathrm{~cm}^{-1}$ are attributed to deformational oscillation of $-\mathrm{CH}_{3}$ groups and other oscillation from the bonds between carbon atoms. The absorption bands in the spectral region in 1456 and $1359 \mathrm{~cm}^{-1}$ characteristic of bending vibrations of methylene and methyl groups in the polyol chain [19, 33]. Characteristic peak of $-\mathrm{CN}$ bond attributed to primary amines appears at $1313 \mathrm{~cm}^{-1}$ [34]. In the region $1163-1138 \mathrm{~cm}^{-1}$ and $1076-1046 \mathrm{~cm}^{-1}$ appear the stretching vibrations of
$\mathrm{C}-\mathrm{O}-\mathrm{C}$ and $\mathrm{C}-\mathrm{C}-\mathrm{O}$ (stretch), respectively [35]. These peaks are characteristic for ester polyol.

In Fig. 5b, c the spectra of glycerolysates with different mass ratios and virgin polyol are shown. Glycerolysates are indicating similar structure to commercial polyol due to the presence of the main similar bands, however some differences must be appreciated. The main difference to be noted can be observed in the range of $3600-3200 \mathrm{~cm}^{-1}$ where for virgin polyol the band did not occur as the band is related with remaining glycerine in the reaction media. Moreover, that band presents higher intensity for lower PU/GL mass ratio. The higher content of hydroxyl groups in the recovered polyol is due to the partial solubility of glycerine in the glycerolysate. The peak is very intensive due to high $\mathrm{OH}$ number of the glycerine in comparison to the $\mathrm{OH}$ number of the raw polyester polyol (54-58 $\mathrm{mg} \mathrm{KOH} \mathrm{g}^{-1}$ ). Another difference to be commented is the absence in the raw polyester polyol FTIR of the peak at $3363 \mathrm{~cm}^{-1}$, associated with urethane band, which indicates the presence of PU oligomers in the recovered product Moreover, glycerolysates FTIRs show a band in the region $1612-1510 \mathrm{~cm}^{-1}$ attributed to $-\mathrm{NH}$ groups, corresponding to glycerolysis by-products.

${ }^{1} \mathrm{H}$ NMR spectra of two chosen glycerolysates in comparison with that of the virgin polyol are shown in Fig. 6. The polyol and MDA (methylenediphenyl diamine) structures are shown in Fig. 6 and the primary protons in these compounds are marked by letters and assigned to peaks in the spectra. There can be distinguished several characteristic peaks at $1.7 \mathrm{ppm}\left(-\mathrm{CH}_{2}-\right), 2.3 \mathrm{ppm}$ (ester $-\mathrm{CH}_{2}-\mathrm{C}(\mathrm{O})-\mathrm{O}-$ ) and $3.8-4.2 \mathrm{ppm}\left(-\mathrm{CH}_{2}-\mathrm{O}-\right)$ in ${ }^{1} \mathrm{HNMR}$ spectra of glycerolysates and the virgin polyol that indicate their structural similarity. However, the presence of glycerolysate contamination in comparison with a polyol, as an aromatic amine (i.e., MDA) and carbamates
Fig. 3 Schematic reaction of forming monocarbamates during polyurethane glycerolysis

Fig. 4 Schematic reaction of forming dicarbamates during polyurethane glycerolysis
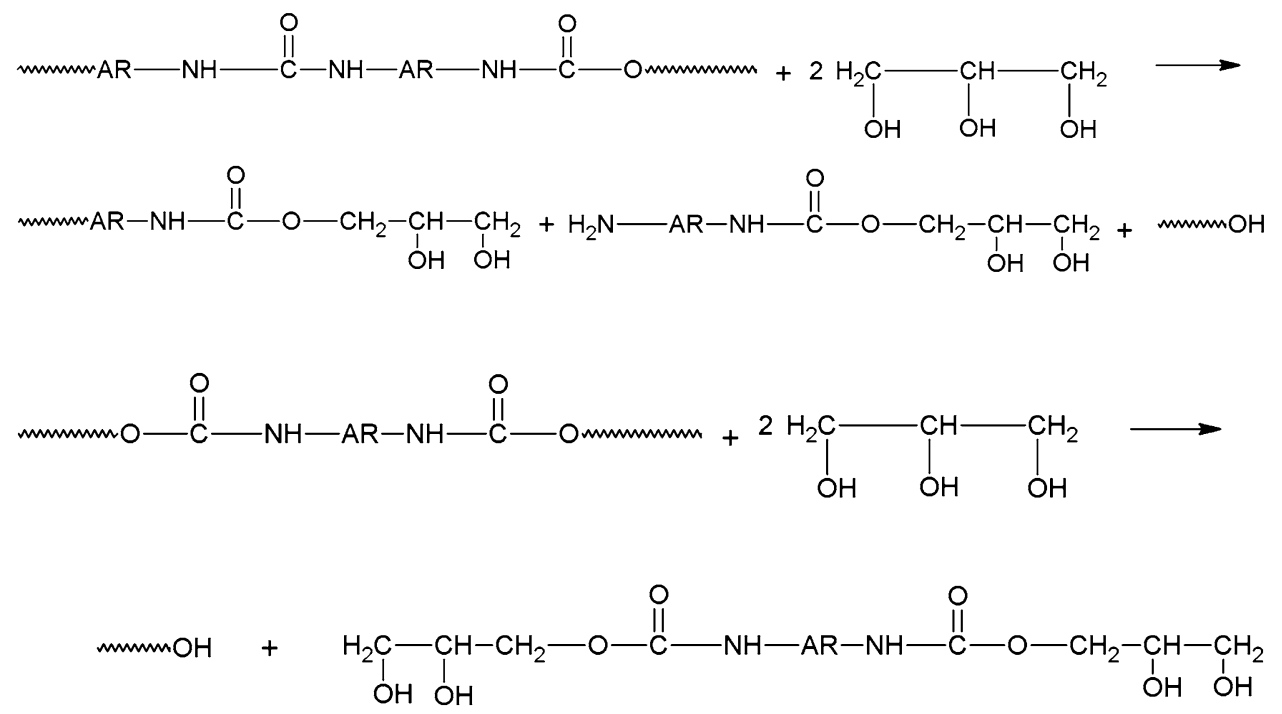

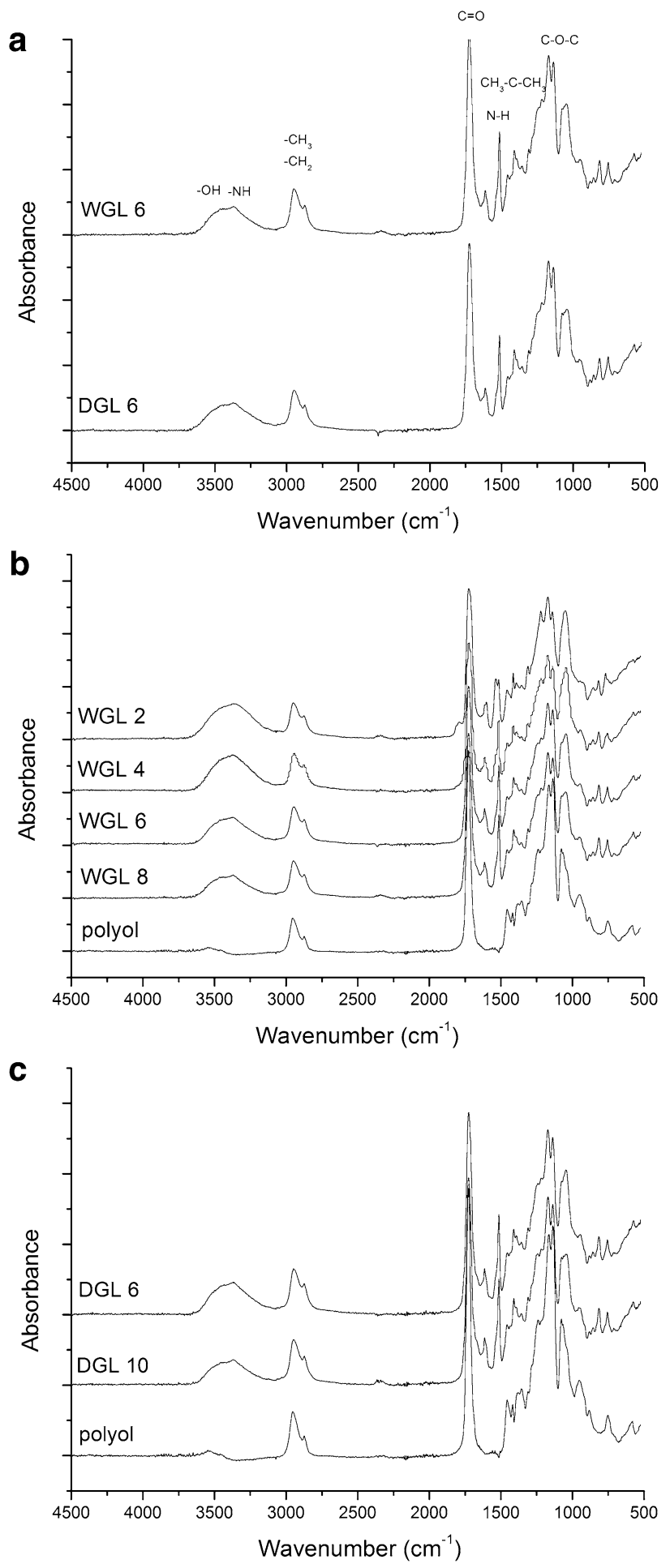

Fig. 5 FTIR spectra of a glycerolysates WGL 6 and DGL 6, b glycerolysates coded WGL and commercial polyol, $\mathbf{c}$ glycerolysates coded DGL and commercial polyol

can be distinguished in additional peaks at $3.9 \mathrm{ppm}$ $\left(-\mathrm{CH}_{2}-\right.$ between two aromatic rings) and 6.6 and $7.1 \mathrm{ppm}$ (-CH- from aromatic rings) appear.
GPC chromatograms of glycerolysates obtained through glycerolysis of PU elastomer with waste or distilled glycerine are presented in Fig. 7a-c. Polyurethane is degraded by glycerine and converted into smaller fragments (urethane oligomers), releasing polyol into reaction media. Figure 7a, b show the GPC chromatographs of samples with increasing PU/GL mass ratios from 2:1 to 10:1, respectively. In Fig. 7.can be observed six different peaks. The polyol is released from the first stages of degradation; this means that there is a wide distribution of molecular weights [36]. The first high-intensity peak, appearing ca. 13 min retention time for all samples, is assigned to recovered polyol and urethane oligomers and presents a molecular weight ranging from 1100 to $1700 \mathrm{~g} \mathrm{~mol}^{-1}$ depending on PU/GL mass ratio (Table 2). This indicates that the applied glycerolysis conditions allowed polyurethane degradation to obtain the glycerolysates, but not pure virgin polyol, whose molecular weight measured by GPC is $1240 \mathrm{~g} \mathrm{~mol}^{-1}$. The presence of oligomers can be seen on the left side of the first peak, as the peak is broader than for virgin polyol. However, peak 2 (except WGL 2 in Fig. 7a) also corresponds with the high molecular carbamates (reaction byproducts) (777-850 $\mathrm{g} \mathrm{mol}^{-1}$, Table 2), decreasing with the reaction time. That indicates partially recovery of polyol from degradation process. The molecular weight of byproducts are ca. 540, 400 and $280 \mathrm{~g} \mathrm{~mol}^{-1}$ and correspond to the glycerolysis by-products: low weight carbamates (mono- and dicarbamates) and aromatic amines derived from the glycerine substitution in the urethane bond [17]. The peaks 6 are assigned to the remaining reactant-glycerine $\left(\mathrm{Mw} \approx 108 \mathrm{~g} \mathrm{~mol}^{-1}\right)$, similar to glycerine molecular weight $\left(\approx 100 \mathrm{~g} \mathrm{~mol}^{-1}\right)$ for which the chromatogram is clear and well-defined peak can be seen at retention time similar to peak 6. Molecular weight, obtained from GPC, for both glycerine, is ca. $100 \mathrm{~g} \mathrm{~mol}^{-1}$.

In Fig. 7c, the comparison of WGL 6 and DGL 6 chromatograms are shown. The curves show a comparable pattern and glycerolysates indicate very similar MWD, what is presented in Tables 2 and 3, as the molecular weights of all appearing peaks and percentage by weight for WGL 6 and DGL 6 are approximate. This suggests that the type of glycerine does not influence in a great extension the molecular weight of the obtained glycerolysates. Moreover, it was also corroborated by means of FTIR results that the structure of WGL6 and DGL6 are almost the same (Fig. 5a).

The concentrations of compounds were obtained from the areas integration of GPC chromatogram due to each peak represents a substance of a different molecular weight (Table 3). The greater area of peak 1 means that higher concentration of urethane oligomers and recovered polyol were obtained. The primary product of glycerolysis is glycerolysate, containing approx. $40 \%$ of recovered polyol and ca. $20 \%$ of oligomers (Table 3 ), which may be reused in 
Fig. $6{ }^{1} \mathrm{H}$ NMR spectra of glycerolysates WGL2, DGL10 and origin polyol
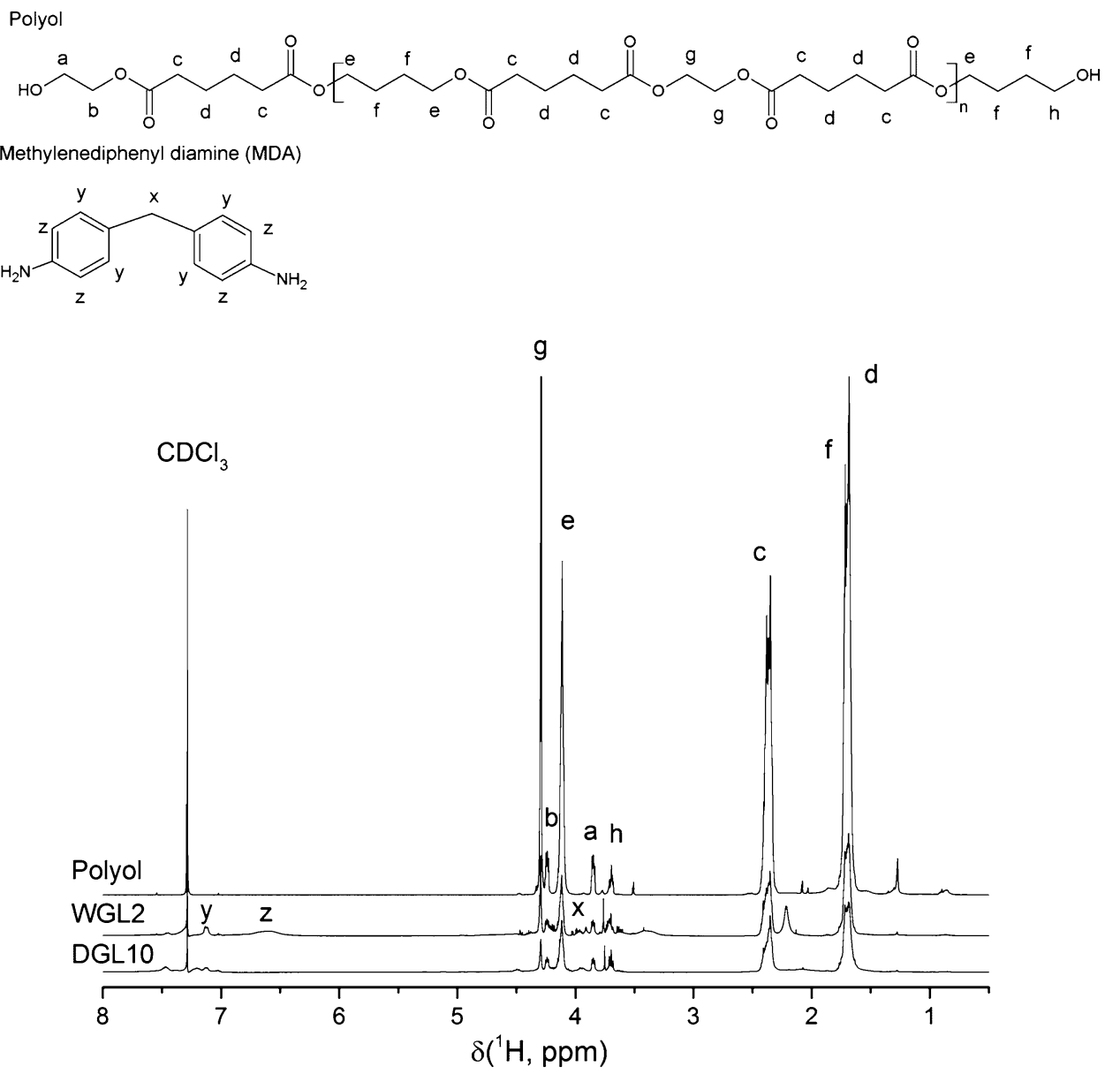

new polyurethane synthesis. It can be concluded that the most optimal for re-synthesis of polyurethane may be glycerolysates with PU/GL mass ratios of $6: 1$ and $8: 1$ due to the low content of by-products and a high percentage of recovered polyol and oligomers. The properties of the glycerolysates seen in the GPC and FTIR seem to make them reformulable.

In Table 4 the average molecular mass, polydispersity (PD) and functionality (f) are shown. Chromatographic analysis showed that glycerolysis allowed obtaining glycerolysates with the mean polydispersity lower than 1.8. This is advantageous because glycerolysates are supposed to serve as a component in the production of urethane polymers. High polymolecularity could significantly reduce or exclude the application of such components in the manufacture of PUs that are characterised by ordered structure that influences sought after properties of the product [17]. Hydroxyl value decreases from 512 to $183 \mathrm{mg} \mathrm{KOH} \mathrm{g}^{-1}$ when PU/GL mass ratio is increased and it is due to the lower quantity of unreacted glycerine. Glycerolysates obtained via reaction of polyurethane elastomer with crude glycerine (Table 4) had slightly lower values of hydroxyl number, than those obtained with distilled glycerine. It is favourable because obtained semi-products will indicate higher molecular mass and that creates the possibility to direct use in polymer urethane synthesis. However, the properties of the final product are not in the range of the raw polyester polyol, which is $54-58 \mathrm{mg} \mathrm{KOH} \mathrm{g}^{-1}$. These higher $\mathrm{OH}$ values are due to the high concentrations of by-products and glycerine in the glycerolysates which are in accordance with FTIR results (Fig. 5) (peak at $3470 \mathrm{~cm}^{-1}$ coming from $\mathrm{OH}$ groups hydroxyl compounds) and with the products concentration obtained by means of GPC and showed in Table 3. Furthermore, the number average molecular weight of glycerolysates (663-879 $\left.\mathrm{g} \mathrm{mol}^{-1}\right)$ is lower than that of the virgin polyol $\left(M_{n G P C}=1240 \mathrm{~g} \mathrm{~mol}^{-1}\right)$, and it is probably caused due to the presence of small molecular weight by-products. However, semi-products with similar $\mathrm{OH}$ number and molecular weight can be suitable for viscoelastic polyurethane foam [37].

Apart from structural analysis, also the physical properties were determined, and the results are shown in Table 4. The density of glycerolysates is ranging from 1.156 to $1.207 \mathrm{~g} \mathrm{~cm}^{-3}$, and the highest density value is attributed to WGL 2 sample what can be related to the presence of 

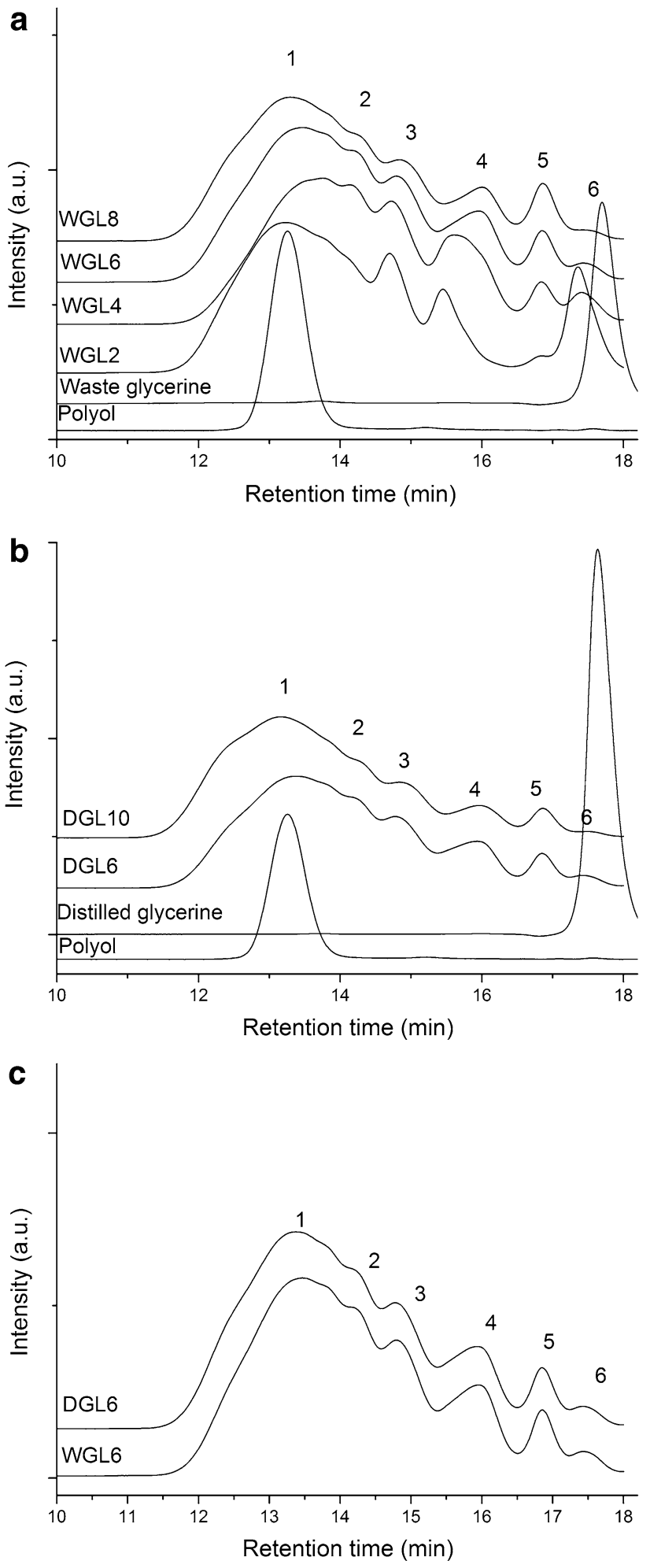

Fig. 7 GPC chromatogram of the glycerolysates: a WGL 2-8, polyol and waste glycerine, b DGL 6, DGL 10 polyol and distilled glycerine, c comparison of the glycerolysates WGL 6 and DGL 6 glycerine which presents a higher density than polyurethane elastomer. Density value has demonstrated not to be a function of the glycerine type. The viscosity of WGL and DGL samples shows increasing trend with increasing PU/ GL mass ratio, what is related to higher molecular weight. Furthermore, the viscosity of DGL samples is slightly higher than for WGL. These properties play a significant role in the further reuse of the polyol since small changes can affect negatively forming a new material.

\section{Conclusions}

The feasibility of the glycerolysis process of elastomeric polyurethane scraps, using as transesterification agents both distilled and waste (crude) glycerine, derived as a by-product from biodiesel production, has been demonstrated. Two types of glycerine reagents have been tested, waste glycerol from biodiesel production (purity $80 \%$ ) and chemical grade purity glycerine (purity 99.5\%), whereas potassium acetate has been used as glycerolysis catalyst. Transesterification reaction has been carried out successfully at temperature $225-230^{\circ} \mathrm{C}$, under atmospheric pressure resulting in glycerolysates containing a relevant percentage of recovered polyester polyol. The FTIR spectra confirmed that the type of glycerine has insignificant influence on the chemical composition of glycerolysates as demonstrated by similar absorption bands in FTIR spectra (Fig. 5). The chemical structure of glycerolysates is quite similar to the virgin polyol one due to the vibration bands appear in the same regions. The spectra differ mainly appearing stretching and bending vibration, respectively at 3363,1516 and $1612 \mathrm{~cm}^{-1}$, which are corresponding to $-\mathrm{NH}$ groups originated from urethane bonds and starting isocyanates. That was also confirmed by ${ }^{1} \mathrm{HNMR}$ spectroscopy as the spectra of glycerolysate were similar to the polyol one. The GPC chromatograms confirmed the presence of several byproducts, mainly carbamates and amines, in the recovered glycerolysates. However, the peaks of higher intensity in the chromatograms have been attributed to the urethane oligomers and recovered polyol, whereas the low molecular weight peaks have been assigned to by-products and unreacted glycerine. It has been demonstrated that the polyurethane decomposition resulted in glycerolysates with a molecular weight ranging from 800 to $1300 \mathrm{~g} \mathrm{~mol}^{-1}$. Semi-products with similar $\mathrm{OH}$ number and molecular weight can be suitable for viscoelastic polyurethane foam. Furthermore, adopted excess of polyurethane waste to glycerine mass ratio (from 2 to 10 ) allowed the recycling of a greater amount of waste without worsening of glycerolysates properties. In addition to the management of waste, the properties of the recovered 
Table 2 GPC results of the glycerolysates, where $M_{p 1}$ represents $M_{w}$ of first peak etc

\begin{tabular}{|c|c|c|c|c|c|c|}
\hline Sample & $\mathrm{M}_{\mathrm{p} 1}\left(\mathrm{~g} \mathrm{~mol}^{-1}\right)$ & $\mathrm{M}_{\mathrm{p} 2}\left(\mathrm{~g} \mathrm{~mol}^{-1}\right)$ & $\mathrm{M}_{\mathrm{p} 3}\left(\mathrm{~g} \mathrm{~mol}^{-1}\right)$ & $\mathrm{M}_{\mathrm{p} 4}\left(\mathrm{~g} \mathrm{~mol}^{-1}\right)$ & $\mathrm{M}_{\mathrm{p} 5}\left(\mathrm{~g} \mathrm{~mol}^{-1}\right)$ & $\mathrm{M}_{\mathrm{p} 6}\left(\mathrm{~g} \mathrm{~mol}^{-1}\right)$ \\
\hline Polyol & 1240 & - & - & - & - & - \\
\hline WGL 2 & 1638 & - & 571 & 408 & 293 & 119 \\
\hline WGL 4 & 1129 & 850 & 567 & 398 & 277 & 108 \\
\hline WGL 6 & 1380 & 815 & 540 & 384 & 277 & 108 \\
\hline WGL 8 & 1548 & 788 & 533 & 384 & 277 & 108 \\
\hline DGL 6 & 1444 & 810 & 543 & 386 & 277 & 108 \\
\hline DGL 10 & 1721 & 777 & 518 & 385 & 282 & 108 \\
\hline Waste glycerine & - & - & - & - & - & $\approx 100$ \\
\hline Distilled glycerine & - & - & - & - & - & $\approx 100$ \\
\hline
\end{tabular}

Table 3 Products concentration in the glycerolysates depending on the mass PU/GL ratio and glycerine type

\begin{tabular}{|c|c|c|c|c|c|c|c|}
\hline \multirow[t]{2}{*}{ Products } & \multicolumn{7}{|c|}{$\%$ by weight } \\
\hline & Oligomers & Recovered polyol & By-product 1 & By-product 2 & By-product 3 & By-product 4 & Glycerine \\
\hline WGL 2 & 18.83 & 44.68 & - & 14.76 & 10.03 & 1.03 & 10.52 \\
\hline WGL 4 & 24.25 & 19.71 & 15.05 & 16.53 & 17.43 & 4.06 & 2.96 \\
\hline WGL 6 & 20.98 & 31.53 & 13.51 & 15.08 & 12.68 & 4.67 & 1.55 \\
\hline WGL 8 & 18.69 & 38.83 & 13.10 & 12.91 & 9.40 & 6.10 & 0.95 \\
\hline DGL 6 & 17.94 & 37.48 & 13.07 & 13.87 & 11.70 & 4.49 & 1.5 \\
\hline DGL 10 & 21.15 & 44.67 & 11.80 & 10.50 & 7.37 & 3.84 & 0.67 \\
\hline
\end{tabular}

Table 4 Characteristic of obtained glycerolysates

\begin{tabular}{|c|c|c|c|c|c|c|c|}
\hline Glycerolysate code & $\mathrm{M}_{\mathrm{n}}\left(\mathrm{g} \mathrm{mol}^{-1}\right)$ & $\mathrm{M}_{\mathrm{w}}\left(\mathrm{g} \mathrm{mol}^{-1}\right)$ & PD & $\begin{array}{l}\mathrm{OH}_{\text {number }} \\
\left(\mathrm{mg} \mathrm{KOH} \mathrm{g}^{-1}\right)\end{array}$ & $\mathrm{f}$ & $\begin{array}{l}\mathrm{d} \text { at } 25^{\circ} \mathrm{C} \\
\left(\mathrm{g} \mathrm{cm}^{-3}\right)\end{array}$ & $\eta$ at $70^{\circ} \mathrm{C}(\mathrm{Pa} \cdot \mathrm{s})$ \\
\hline WGL 2 & 663 & 1181 & 1.78 & 511 & 6.04 & 1.207 & 0.59 \\
\hline WGL 4 & 652 & 802 & 1.23 & 331 & 3.84 & 1.191 & 0.36 \\
\hline WGL 6 & 731 & 980 & 1.34 & 216 & 2.81 & 1.183 & 0.40 \\
\hline WGL 8 & 792 & 1116 & 1.41 & 208 & 2.93 & 1.182 & 0.55 \\
\hline DGL 6 & 765 & 1041 & 1.36 & 211 & 2.87 & 1.184 & 0.56 \\
\hline DGL 10 & 879 & 1319 & 1.50 & 183 & 2.86 & 1.167 & 0.99 \\
\hline
\end{tabular}

glycerolysates are suitable to be employed in a further synthesis process of new polyurethane specialties (in the form of foam and elastomer), replacing a part of petrochemical polyol.

Acknowledgements The authors wish to thank Rafineria Trzebinia S.A. (Poland) and STANLAB Sp. J. for kindly providing glycerine.

\section{Compliance with Ethical Standards}

Conflict of interest The authors declare that they have no conflict of interest.

Open Access This article is distributed under the terms of the Creative Commons Attribution 4.0 International License (http:// creativecommons.org/licenses/by/4.0/), which permits unrestricted use, distribution, and reproduction in any medium, provided you give appropriate credit to the original author(s) and the source, provide a link to the Creative Commons license, and indicate if changes were made.

\section{References}

1. Research Grand View (2014) Polyurethane (PU) Market Analysis by Product (Rigid Foam, Flexible Foam, Coatings, Adhesives \& Sealants, Elastomers), By End-use (Furniture and Interiors, Construction, Electronics \& Appliances, Automotive, Footwear, Packaging) and Segment Forecasts To 2020

2. Cregut M, Bedas M, Durand MJ, Thouand G (2013) Biotechnol Adv 31:1634-3647 
3. Plastics Europe (2015) Plastics-the facts 2014/2015: An analysis of European plastics production, demand and waste data. Plastics Europe, Salzburg

4. Czupryński B, Paciorek-sadowska J, Liszkowska J, Czupryńska J (2002) Polimery 47:104-109.

5. Datta J, Rohn M (2007) Polimery 52:579-582.

6. Zia KM, Bhatti HN, Ahmad Bhatti I (2007) React Funct Polym 67:675-692

7. Yang W, Dong Q, Liu S et al (2012) Procedia. Environ Sci 16:167-175

8. Behrendt G, Naber BW (2009) J Univ Chem Technol Metall 44:3-23.

9. Datta J, Kopczyńska P (2016) Crit Rev Environ Sci Technol 46:905-946

10. Molero C, de Lucas A, Rodríguez JF (2009) Polym Degrad Stab 94:533-539.

11. Molero C, de Lucas A, Rodríguez JF (2006) Polym Degrad Stab 91:221-228.

12. Murai M, Sanou M, Fujimoto T, Baba F (2003) J Cell Plast 39:15-27.

13. Simón D, García MT, De Lucas A, et al (2013) Polym Degrad Stab 98:144-149.

14. Nikje MMA, Nikrah M (2007) Polym Plast Technol Eng 37-41.

15. Hekmatjoo N, Ahmadi Z, Afshar Taromi F, et al (2015) Polym Int 64:1111-1120.

16. Zhu P, Cao ZB, Chen $\mathrm{Y}$ et al (2014) Environ Technol 35:2676-2684

17. Datta J (2012) J Therm Anal Calorim 109:517-520

18. Molero C, de Lucas A, Rodríguez JF (2009) J Mater Cycles Waste Manag 11:130-132.

19. Nikje MMA, Nikrah M (2007) Polym Bull 58:411-423.

20. Shamsi R, Abdouss M, Sadeghi GMM, Taromi FA (2009) Polym Int 58:22-30.
21. Simón D, Borreguero AM, de Lucas A, Rodríguez JF (2014) Polym Degrad Stab 109:115-121.

22. Simón D, Borreguero AM, de Lucas A, Rodríguez JF (2015) Polym Degrad Stab 116:23-35.

23. Simón D, de Lucas A, Rodriguez JF, et al (2016) Polym Degrad Stab 133:119-130.

24. Simón D, Borreguero AM, de Lucas A, et al (2014) J Mater Cycles Waste Manag 16:525-532.

25. Datta J, Rohn M (2007) Polimery 52:625-710.

26. Simón D, Borreguero AM, de Lucas A, Rodríguez JF (2015) Polym Degrad Stab 121:126-136.

27. Kopczynska P, Datta J (2016) Polym Int 65:946-954.

28. Melcer A, Klugman-Radziemska E, Ciunel K (2011) Arch Gospod Odpad i Ochr Środowiska 13:1-20.

29. Fangrui M, Milford HA (1999) Bioresour Technol 70:1-15

30. Datta J, Kopczyńska P (2015) Patent Application Poland EP 1546007

31. Molero C, de Lucas A, Rodríguez JF (2008) Polym Degrad Stab 93:353-361.

32. Nikje MMA, Nikrah M, Haghshenas M (2007) Polym Bull 59:91-104.

33. Coates J (2000) Interpretation of infrared spectra, A practical approach. Wiley, Chichester

34. Datta J, Głowińska E (2014) Ind Crops Prod 61:84-91

35. Umare SS, Chandure AS, Pandey RA (2007) Polym Degrad Stab 92:464-479.

36. Molero C, de Lucas A, Rodríguez JF (2006) Polym Degrad Stab 91:894-901

37. Prociak A, Szczepkowski L (2014) Elastic and viscoelastic foams. In: Ochmańska J (ed) Polyurethane Mater. PWN, Warszawa, \&, pp 109-154 